\title{
Macromonomers from AGET Activation of Poly( $n$-butyl acrylate) Precursors: Radical Transfer Pathways and Midchain Radical Migration
}

\author{
Joke Vandenbergh and Thomas Junkers* \\ Polymer Reaction Design Group, Institute for Materials Research (IMO), Universiteit Hasselt, Agoralaan Building D, B-3590 \\ Diepenbeek, Belgium
}

ABSTRACT: Macromonomers are synthesized from AGET activation of poly ( $n$-butyl acrylate), $\mathrm{P}(n \mathrm{BuA})$, synthesized via ATRP. Reactivation of the polymer chains is achieved at $140{ }^{\circ} \mathrm{C}$ using $\mathrm{Sn}(\mathrm{EH})_{2}$ as reducing agent. Under such conditions, $\mathrm{P}(n \mathrm{BuA})$ macroradicals undergo fast chain transfer reactions forming midchain radicals, MCR, followed by $\beta$ scission reactions leading to unsaturated macromonomers. Furthermore, intermolecular transfer-to-polymer reactions lead to considerable amounts of hydrogen-terminated products. Soft ionization mass

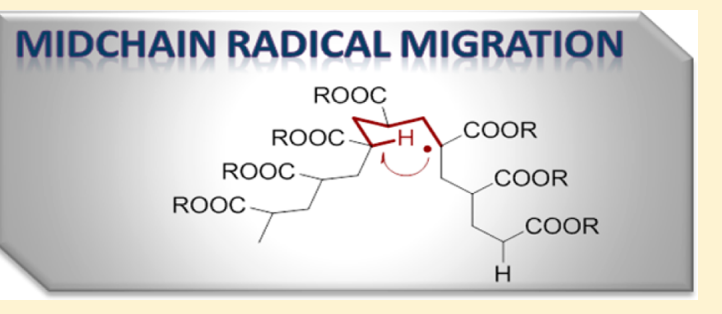
spectrometry of product samples reveals that under very dilute conditions the macromonomer formation is predominant over the hydrogen transfer reaction of the macroradicals, and macromonomers with overall $80 \%$ end-group purity can be achieved, which is, however, accompanied by a reduction in molecular weight from 2100 to $1300 \mathrm{~g} \mathrm{~mol}^{-1}$ and an increase in polydispersity from 1.33 to roughly 1.5. Furthermore, we demonstrate not only that macromonomers under these reaction conditions are formed through simple backbiting $/ \beta$-scission via six-membered ring transition structures but that also random transfer plays a considerable role. Finally, due to the observation of a size-selective reaction pathway that favors generation of macromonomers with only odd numbers of monomer units on the backbone, a new MCR migration mechanism is postulated, which allows MCRs to move along the backbone.

\section{INTRODUCTION}

Well-defined polymer materials with predetermined molecular weight, narrow polydispersity, and high end-group fidelity have become accessible via controlled/living radical polymerization techniques, with reversible addition-fragmentation chain transfer polymerization (RAFT), ${ }^{1,2}$ atom transfer radical polymerization (ATRP), ${ }^{3}$ and nitroxide-mediated polymerization $(\mathrm{NMP})^{4}$ being the most prominent developments during the past two decades. Via these controlled radical polymerization methodologies, not only polymers can be controlled in terms of chain length and dispersity but also (co)monomer and (co)polymer composition, topology, microstructure, and end-group functionalities for further reaction such as radical coupling, ${ }^{5}$ click-chemistry approaches ${ }^{6-8}$ to generate very well-defined, but nevertheless highly complex, polymer architectures such as branched polymers, block-, graft-, comb-, or star-polymers with unique physical properties and self-assembly abilities. ${ }^{9,10}$

One such specific type of polymeric building block for such applications is the so-called macromonomer (MM). ${ }^{11}$ MMs are oligomeric or polymeric species with an unsaturated vinyl terminus that can themselves act as polymerizable functional group. MMs can be synthesized via several pathways. For example, low-polydispersity polymers obtained from ATRP can be transferred into MMs via esterification reactions on specific initiator groups or via click reactions on the polymers end groups. ${ }^{12,13}$ Furthermore, the use of classical additionfragmentation chain transfer (AFCT) polymerization can lead to $\mathrm{MMs}^{14}$ as well as cobalt-mediated catalytic chain transfer copolymerizations. $^{15}$ Interestingly, formation of MMs was also observed as a side-product in conventional free radical polymerization (FRP) of acrylates at high temperatures stemming from backbiting/ $\beta$-scission reactions (see below), ${ }^{16-18}$ which was implemented by Chiefari et al. in a synthetic route to deliberately form uniform MMs via FRP in high yields directly from uncontrolled acrylate polymerizations using a one-pot synthesis procedure. ${ }^{19,20}$ While this method worked quite well and helped tremendously to understand the true nature of acrylate polymerizations, ${ }^{21}$ it produced MMs with large polydispersity indices since the MMs were the product of a free radical polymerization. It is well-known that during the FRP of acrylates chain transfer reactions take place, which inevitably will form midchain radicals (MCR). ${ }^{22,23}$ Already at relatively low temperatures, such MCR species are formed, and at conventional polymerization temperatures, i.e. $60{ }^{\circ} \mathrm{C}$, already close to $80 \%$ of radicals are of the MCR type. MCRs can undergo termination and propagation reactions, leading to a branched polymer product. At higher temperatures-well above $80^{\circ} \mathrm{C}$ - a third reaction channel opens up and also $\beta$-scission reactions may occur, giving rise to secondary radicals and unsaturated MMs (see Scheme 1). For the transfer reaction itself, it is worthwhile to mention that three

Received: June 18, 2012

Revised: August 1, 2012

Published: August 24, 2012 
Scheme 1. General Mechanism of MCR Formation/ $\beta$-Scission Occurring at High-Temperature Acrylate Polymerization

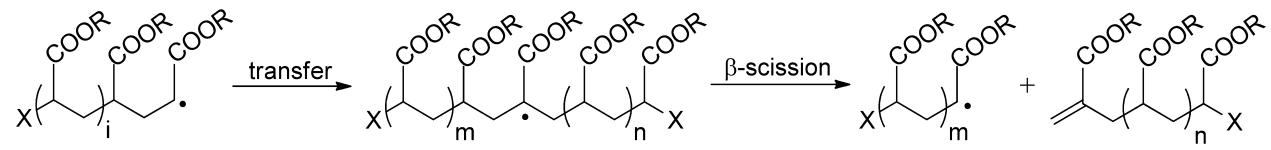

Scheme 2. Mechanism of MCR Formation, Migration, and Final $\beta$-Scission, Leading to Size-Specific MM Species

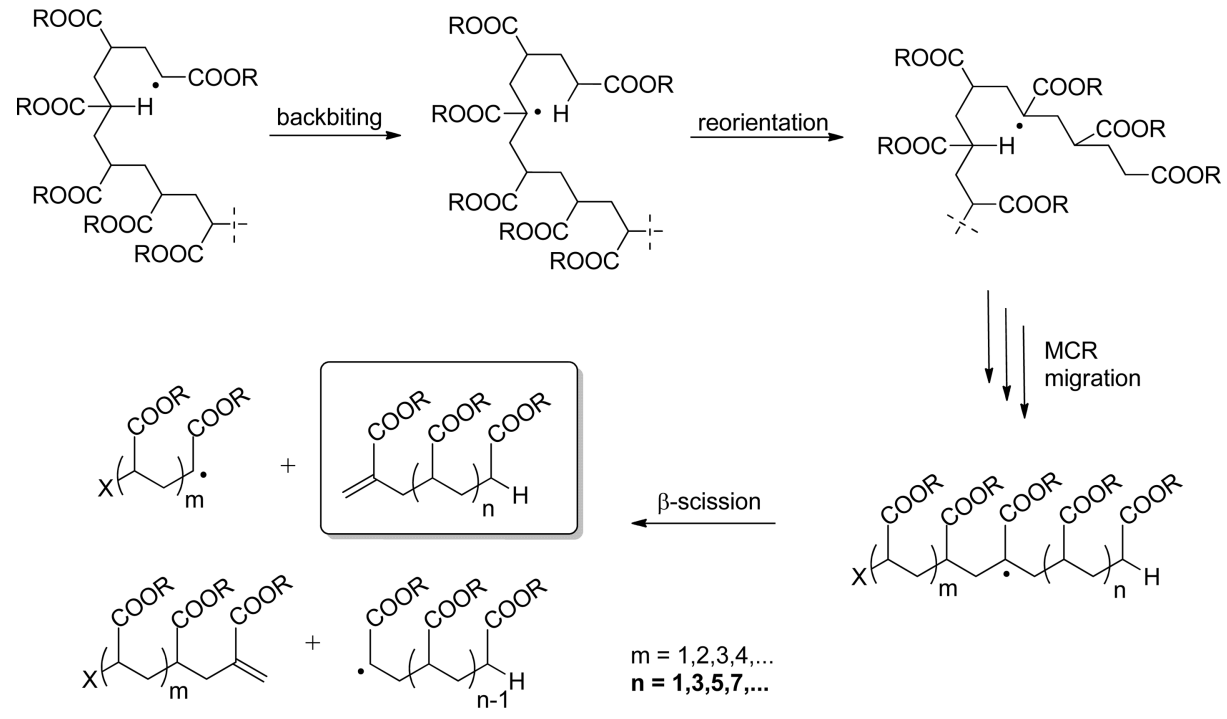

independent processes lead to the formation of MCRs. One is the so-called backbiting step, in which the MCR is formed at the chain end via a six-membered ring transition structure (compare Scheme 2 for details). Second, also random intramolecular transfer to remote position on the backbone may occur, and last, but not least, also random intermolecular transfer to neighboring chains may play a role. A distinction of these three processes is relatively complicated, and thus they are often not clearly differentiated, even though each step is attributed with a distinct reaction rate coefficient and molarity.

Junkers and Barner-Kowollik refined the method of Chiefari et al. and elucidated the reaction mechanism behind MM formation via detailed electrospray ionization mass spectrometry (ESI-MS) studies and kinetic simulations to explore the boundaries and limitations of MM synthesis and acrylate polymerization in general. $^{21,24-28}$ Indeed, it was shown that acrylate polymerizations at high temperature and conversion resemble (reversible) addition-fragmentation reaction systems, ${ }^{29}$ explaining why MMs of such high purity are accessible in the described way. Later, a diverse MM library was made using this approach, and the copolymerization behavior of $n$ butyl acrylate MMs was investigated. ${ }^{30,31}$ Furthermore, MMs were applied in synthetic approaches to generate more complex materials out of these building blocks. ${ }^{10,32}$

For the current study we aimed at applying the principle of MM synthesis from high-temperature acrylate polymerization to a precursor system in order to make identical acrylate MMs with low polydispersity. Therefore, poly(n-butyl acrylate) $\mathrm{P}(n \mathrm{BuA})$ polymers were synthesized via conventional ATRP. In order to reactivate the polymer chains, conditions applied in activators generated by electron transfer ATRP (AGET-ATRP) are used. ${ }^{33,34}$ With AGET, a $\mathrm{Cu}(\mathrm{II})$ species and a reducing agent such as $\mathrm{Sn}(\mathrm{EH})_{2}$ are added to the precursor ATRP polymer. The reducing agent will quickly convert all inactive $\mathrm{Cu}$ (II) species into active $\mathrm{Cu}(\mathrm{I})$, which in turn will reactivate the dormant ATRP polymer chains. Since the radical nature of radicals in ATRP are similar to radicals generated by conventional radical polymerizations, one would expect atom transfer radical coupling reactions to occur ${ }^{35}$ in the absence of monomer, as well as other termination reactions into dead polymer chains. However, when applying high reaction temperatures $\left(140{ }^{\circ} \mathrm{C}\right)$, it is presumed that the reactivated polymer chains will undergo chain transfer to MCRs followed by $\beta$-scission into MMs faster than termination via disproportionation. To investigate this hypothesis, the resulting products will be assessed with NMR, SEC, and detailed ESI-MS analysis. Furthermore, this study allows us to investigate the MM formation independently without having to deal with propagation reactions that are simultaneously occurring when using Chiefari's normal FRP method. It should be noted that AGET-ATRP conditions are chosen for the simple reason that it allows to start the reaction after heat-up of the reaction mixture.

As a result, more insight into the kinetics and mechanism for MM formation are obtained. If the current model for hightemperature acrylate polymerization was correct, then one would expect that backbiting via the six-membered ring transition structure was the favored process of transfer, yielding MMs with more or less unchanged average size compared to the starting ATRP polymer. In what follows, we will demonstrate that MMs can be indeed formed in the abovedescribed process but that the random transfer plays a larger than normally assumed role in obtaining a pure product. A clear distinction between random transfer and six-membered ringbackbiting can be made on the basis of the obtained product data, i.e., the size distribution and the product distribution obtained by ESI-MS. Additionally, due to the observation of a size-selective reaction pathway, new transfer routes will be discussed, namely a MCR migration mechanism, which allows MCRs to move along the backbone. 
Table 1. Reaction Conditions and Results for Different AGET Activation Experiments on Precursor $\mathrm{P}(n \mathrm{BuA})$ (Reaction Temperature $=140{ }^{\circ} \mathrm{C}$, Reaction Time $=3 \mathrm{~h}$ )

\begin{tabular}{|c|c|c|c|c|c|c|c|c|c|}
\hline entry & $\begin{array}{c}\mathrm{P}(n \mathrm{BuA}) \\
\text { (equiv) }\end{array}$ & $\begin{array}{c}\mathrm{CuBr}_{2} \\
\text { (equiv) }\end{array}$ & $\begin{array}{l}\mathrm{ME}_{6} \mathrm{TREN} \\
\text { (equiv) }\end{array}$ & $\begin{array}{c}\mathrm{Sn}(\mathrm{EH})_{2} \\
\text { (equiv) }\end{array}$ & $\begin{array}{l}\text { solvent } \\
(\mathrm{mL})\end{array}$ & $\begin{array}{l}\text { additive } \\
\text { (1.5 equiv) }\end{array}$ & $\begin{array}{c}M_{\mathrm{n}} \\
\left(\mathrm{g} \mathrm{mol}^{-1}\right)\end{array}$ & PDI & $\begin{array}{c}\text { major species in ESI-MS } \\
( \pm 5 \%)\end{array}$ \\
\hline 1 & 1 & 1 & 2 & 0.5 & 1 & \multirow{7}{*}{$\mathrm{C}_{8} \mathrm{H}_{17} \mathrm{SH}$} & 1900 & 1.49 & H-term pol $(64 \%)$ \\
\hline 2 & 1 & 1 & 2 & 0.5 & 1 & & 1900 & 1.40 & H-term pol $(85 \%)$ \\
\hline 3 & 1 & 1 & 2 & 0.5 & 5 & & 1200 & 1.68 & MMs (53\%) \\
\hline 4 & 1 & 1 & 2 & 0.5 & 50 & & 1300 & 1.55 & MMs (79\%) \\
\hline 5 & 1 & 0.2 & 2 & 0.5 & 50 & & 1300 & 1.51 & MMs (71\%) \\
\hline 6 & 1 & 2 & 2 & 0.5 & 50 & & 1500 & 1.49 & MMs (68\%) \\
\hline 7 & 1 & 5 & 10 & 2.5 & 250 & & 1200 & 1.62 & MMs (71\%) \\
\hline
\end{tabular}

\section{EXPERIMENTAL SECTION}

Materials. The monomer $n$-butyl acrylate ( $n$-BuA, Acros, 99\%) was deinhibited over a column of activated basic alumina, prior to use. Copper(I) bromide ( $\mathrm{Cu}^{\mathrm{I}} \mathrm{Br}$, Acros, 98\%) was washed with acetic acid at $80{ }^{\circ} \mathrm{C}$ for $18 \mathrm{~h}$ to remove any soluble oxidized species before being filtered, washed with absolute ethanol, to $\mathrm{pH} 7$, then washed with ethyl ether, and then dried under vacuum. Tris(2-(dimethylamino)ethyl)amine ( $\left.\mathrm{ME}_{6} \mathrm{TREN}\right)$ was synthesized following a literature procedure. $^{36} N, N, N^{\prime}, N^{\prime \prime}, N^{\prime \prime}$-Pentamethyldiethylenetriamine (PMDETA, Acros, 99\%), copper(II) dibromide ( $\mathrm{Cu}^{\mathrm{II}} \mathrm{Br}_{2}$, Sigma-Aldrich, 99.9\%), methyl-2-bromopropionate (MBP, Sigma-Aldrich, 98\%), and tin(II) 2 ethylhexanoate $\left(\mathrm{Sn}(\mathrm{EH})_{2}\right.$, Alfa Aesar, 96\%) were used as received. All solvents used are obtained from commercial sources (Acros and Sigma-Aldrich) and used without further purification.

Characterization. ${ }^{1} \mathrm{H}$ NMR spectra were recorded in deuterated chloroform with a Varian Inova 300 spectrometer at $300 \mathrm{MHz}$ applying a pulse delay of $12 \mathrm{~s}$ using a Varian probe $(5 \mathrm{~mm}$ 4-nucleus AutoSWPFG). Analysis of the MWDs of the polymer samples were performed on a Tosoh EcoSEC operated by PSS WinGPC software, equipped with a PLgel $5.0 \mu \mathrm{m}$ guard column $(50 \times 8 \mathrm{~mm})$, followed by three PLgel $5 \mu \mathrm{m}$ Mixed-C columns $(300 \times 8 \mathrm{~mm})$, and a differential refractive index detector using THF as the eluent at $40{ }^{\circ} \mathrm{C}$

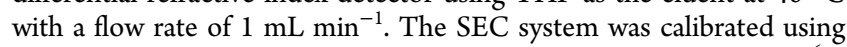
linear narrow polystyrene standards ranging from 474 to $7.5 \times 10^{6} \mathrm{~g}$ $\mathrm{mol}^{-1}\left(\mathrm{PS}\left(K=14.1 \times 10^{-5} \mathrm{dL} \mathrm{g}^{-1}\right.\right.$ and $\left.\alpha=0.70\right)$, and toluene as a flow marker. ESI-MS was performed using an LCQ Fleet mass spectrometer (ThermoFischer Scientific) equipped with an atmospheric pressure ionization source operating in the nebulizer-assisted electrospray mode. The instrument was calibrated in the $m / z$ range 220-2000 using a standard solution containing caffeine, MRFA, and Ultramark 1621. A constant spray voltage of $5 \mathrm{kV}$ was used, and nitrogen at a dimensionless auxiliary gas flow rate of 3 and a dimensionless sheath gas flow rate of 3 were applied. The capillary voltage, the tube lens offset voltage, and the capillary temperature were set to $25 \mathrm{~V}, 120 \mathrm{~V}$, and $275{ }^{\circ} \mathrm{C}$, respectively. A $250 \mu \mathrm{L}$ aliquot of a polymer solution with concentration of $10 \mu \mathrm{g} \mathrm{mL}^{-1}$ was injected. A mixture of THF and methanol (THF:MeOH = 3:2), all HPLC grade, were used as solvent.

General ATRP Polymerization of $n$ BuA. The purified $\mathrm{Cu}(\mathrm{I}) \mathrm{Br}$ ( $0.858 \mathrm{mmol}, 122 \mathrm{mg}, 1.1$ equiv) was added together with $0.062 \mathrm{~mol}$ ( $8 \mathrm{~g}, 80$ equiv) of the monomer $n \mathrm{BuA}$ and $0.780 \mathrm{mmol}(0.130 \mathrm{~g}, 1$ equiv) of $\mathrm{MBP}$ initiator under an inert atmosphere into a sealed Schlenk tube. The Schlenk tube was subjected to three freeze-pumpthaw cycles to remove residual oxygen, after which it was filled with a nitrogen atmosphere. In a separate vial, a mixture of EtOAc $(2.5 \mathrm{~mL}$, 22 vol \%) and $1.716 \mathrm{mmol}$ (0.297 g, 2.2 equiv) of PMDETA ligand was degassed likewise. The reaction mixture in the Schlenk was heated up to $75^{\circ} \mathrm{C}$ in an oil bath. Subsequently, the polymerization is started by adding the degassed solvent-initiator mixture. After a reaction time of $10 \mathrm{~min}$, the polymerization was stopped by cooling in liquid nitrogen and a NMR sample was taken to determine a conversion of $17 \%$. The polymer/monomer mixture was dissolved in THF, and the copper catalyst was removed by passing the diluted reaction mixture over basic alumina. Afterward, the excess of solvent and residual monomer was evaporated, yielding $1.29 \mathrm{~g}$ of $\mathrm{P}(n \mathrm{BuA})$ (1) polymer with $M_{\mathrm{n}}=2100 \mathrm{~g} \mathrm{~mol}^{-1}$ and PDI $=1.33$ (by THF-SEC, $K=12 \times$ $\left.10^{-3}, \alpha=0.7\right)$. ESI-MS analysis reveals a Br-end-group functionality of $95 \%$.

Macromonomer Formation Using AGET Conditions. In a typical experiment, $\mathrm{P}(n \mathrm{BuA})(1)$ ATRP polymer $(26 \mu \mathrm{mol}, 50 \mathrm{mg}, 1$ equiv) was dissolved in $50 \mathrm{~mL}$ of anisole in a Schlenk tube. $\mathrm{Cu}(\mathrm{II}) \mathrm{Br}_{2}$ ( $26 \mu \mathrm{mol}, 6 \mathrm{mg}, 1$ equiv) and $\mathrm{ME}_{6} \mathrm{TREN}(52 \mu \mathrm{mol}, 12 \mathrm{mg}, 2$ equiv) were added; the Schlenk tube was sealed and subjected to three freeze-pump-thaw cycles, after which it was filled with a nitrogen atmosphere. In a separate glass vial a reducing agent $\mathrm{Sn}(\mathrm{EH})_{2}(13$ $\mu \mathrm{mol}, 5.2 \mathrm{mg}, 0.5$ equiv) was dissolved in $0.5 \mathrm{~mL}$ of anisole and degassed by purging with nitrogen for $10 \mathrm{~min}$. The reaction mixture in the Schlenk was heated up to $140{ }^{\circ} \mathrm{C}$ in an oil bath. Subsequently, the reaction was started by adding the degassed solvent-reducing agent mixture. After the desired reaction time was reached, the reaction was stopped by cooling in liquid nitrogen. The product mixture was dissolved in THF, and the copper catalyst was removed by passing the diluted reaction mixture over basic alumina. Afterward, the excess of solvents and residual reducing agent was evaporated, yielding $0.05 \mathrm{~g}$ of product with $M_{\mathrm{n}}=1300 \mathrm{~g} \mathrm{~mol}^{-1}$ and PDI $=1.55$ (by THF-SEC, $K=$ $\left.12 \times 10^{-3}, \alpha=0.7\right) .{ }^{1} \mathrm{H}$ NMR spectroscopy and ESI-MS were performed to reveal the nature and abundance of the different species present in the product samples. Thermal stability of the ATRP polymers was checked by recording SEC chromatograms and ESI-MS spectra of the ATRP precursor polymer before and after heating at 140 ${ }^{\circ} \mathrm{C}$ in solution for $3 \mathrm{~h}$ in absence of copper species.

\section{RESULTS AND DISCUSSION}

With respect to the different types of transfer that are potentially occurring at high temperatures, the outcome of these experiments are highly interesting. If backbiting was the predominant reaction pathway (being much favored over the random transfer events as is most often assumed in literature), then the resulting MM should be more or less of the size of the starting ATRP polymer (since only small radical fragments are chopped off the macroradicals) with each MM still carrying the ATRP initiator unit. If random transfer events are, however, stronger (as indicated in few of the more recent studies into the transfer reaction), ${ }^{28,37}$ then a significant reduction in molecular weight must be expected and a random distribution of end groups should be visible in the product (ATRP initiator unit and protons).

Via conventional ATRP, a precursor $\mathrm{P}(n \mathrm{BuA})$ polymer was obtained with a molar mass of around $M_{n}=2100 \mathrm{~g} \mathrm{~mol}^{-1}$ and PDI $=1.33$. High end-group fidelity was confirmed via ESI-MS. Subsequently, the polymer was reactivated using AGET conditions at a reaction temperature of $140{ }^{\circ} \mathrm{C}$ for $3 \mathrm{~h}$ with the intention to produce uniform, low-polydispersity MMs. The AGET conditions used for reactivating the precursor $\mathrm{P}(n \mathrm{BuA})$ are summarized in Table $1 .{ }^{1} \mathrm{H}$ NMR spectroscopy of the product mixtures displayed typical spectra such as in Figure 1. The resonances at 6.2 and $5.5 \mathrm{ppm}$ correspond to the chemical shifts of the vinyl end groups demonstrating the presence of MM species. 


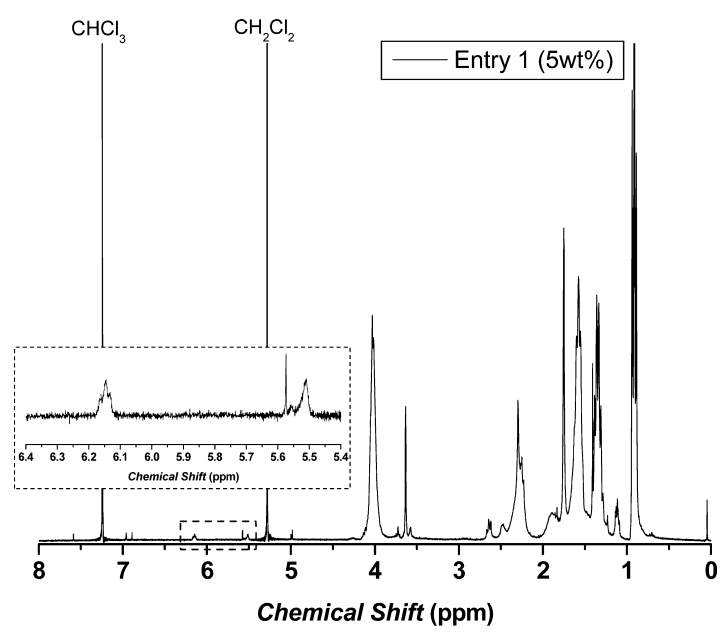

Figure 1. ${ }^{1} \mathrm{H}$ NMR of $\mathrm{P}(n \mathrm{BuA})$ polymer mixture after activation under AGET conditions. Resonances at 6.15 and $5.50 \mathrm{ppm}$ indicate the presence of MM species.

The molecular weight distribution of the resulting MMs is depicted in Figure 2 (for entries 1, 3, and 4 in Table 1).

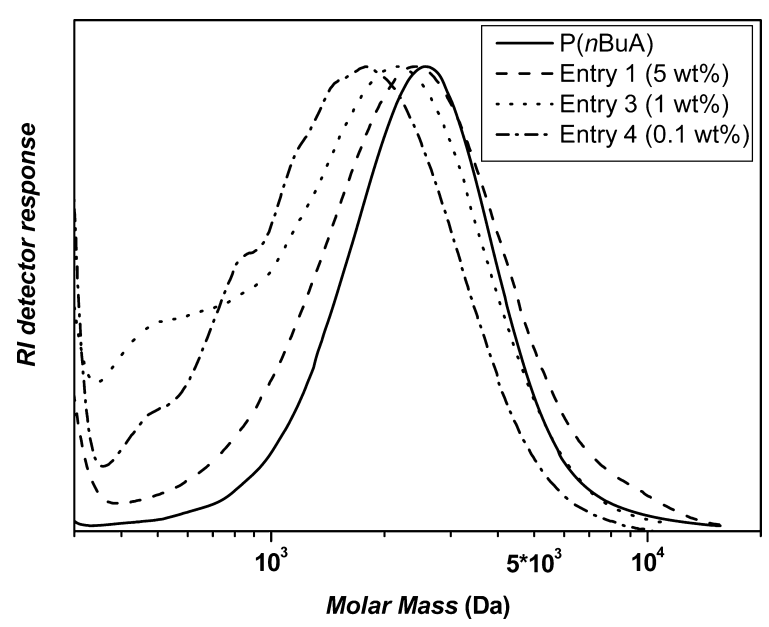

Figure 2. SEC chromatograms of precursor $\mathrm{P}(n \mathrm{BuA})$ and of macromonomer mixtures synthesized in different dilutions at $140{ }^{\circ} \mathrm{C}$ via AGET activation.

Remarkably, higher dilutions led to a substantial shift of the chromatogram toward lower masses. From this observation it is directly evident that intermolecular reactions must play a significant role in the transfer mechanism. It seems that under AGET activation reaction conditions the chain transfer process forming MCRs and subsequent $\beta$-scission into MMs is not only dominated by the intramolecular backbiting via 6-membered ring structures-which would lead to MMs with almost unchanged molar mass-but that random chain transfer (either intra- or intermolecular) plays a substantial role as well.

More insights into the transfer process can be gained via soft ionization mass spectrometry of the samples (see Figures 3 and 4). In all performed reactions a mixture between two MMs species and a hydrogen-terminated product $\mathrm{H}-\mathrm{P}$ was identified in the product spectra. The masses for the observed species are listed in Table 2. The occurring macromonomer species are $\mathrm{MM}^{\mathrm{X}}$, which denote MMs with the ATRP-initiator end group on the nonvinylic side, and $\mathrm{MM}^{\mathrm{H}}$, macromonomers that are proton-terminated (and thus stemming from $\beta$-scission to the other side compared to $\mathrm{MM}^{\mathrm{X}}$ ). Again, if MCR formation via 6membered ring backbiting would be the only dominating process, one would expect to find only $\mathrm{MM}^{\mathrm{X}}$ species (green dots in Figures 3 and 4). However, in most cases, equal amounts of $\mathrm{MM}^{\mathrm{H}}$ (yellow dots in Figures 3 and 4) are observed on average. This is further evidence that random chain transfer is occurring at a considerable level.

Inspection of Figure 4 clearly shows that the ratio of saturated product and MM products changes significantly when the polymer concentration is varied. On first glance one could assume that the saturated product stems from radical termination. This is, however, not the case for most parts. The assigned peak (see structure in Figure 4) fits a $\mathrm{H}$ terminated species that carries the initial ATRP initiator unit on the other chain end $(\mathrm{H}-\mathrm{P})$. If conventional termination was responsible for formation of this species, then one would also expect formation of (i) a product congruent to a termination by combination product and (ii) a second peak at $m / z-2 \mathrm{Da}$ as typically expected for disproportionation peaks. Since both are absent (or only present in small amounts), it can be safely concluded that the presence of the saturated species is not a consequence of termination. This hypothesis is also backed up by experiments where the activator $/ \mathrm{CuBr}_{2}$ concentration was varied to change the rate of radical generation. No significant change in the product composition was seen after such variation. The only other feasible conclusion is that the observed species was formed in hydrogen transfer reactions, e.g., intermolecular transfer to polymer. To test this hypothesis, one batch of precursor polymer was activated in the presence of octane-1-thiol, which can act as a chain transfer reagent. This resulted indeed in an almost exclusive formation of the $\mathrm{H}$ transfer product. The exact mechanism behind the specific $\mathrm{H}$ transfer reaction responsible for creating the $\mathrm{H}$-terminated polymer remains, however, somewhat unclear, especially with regards to its presence in such considerable amounts. By using literature transfer rates such high concentrations in the product cannot be explained. ${ }^{21}$ Thus, either much higher rates than usually assumed must be operational or secondary reactions that so far are have not been identified play a significant role. In principle, also transfer to solvent might explain formation of such product. That it is, however, intermolecular transfer that is responsible for this effect can be easily shown by the dilution experiments that have already been mentioned above in the framework of Figure 2. A high dependency is seen for the ratio between the MMs and the H-terminated dead polymer on the dilution of the reaction mixture. When using a $5 \mathrm{wt} \%$ solution of polymer in solvent, the $\mathrm{H}$-transfer product forms the dominant species. Diluting to $1 \mathrm{wt} \%$, resulted in equal amounts of MMs and $\mathrm{H}$-transfer product and finally, a dilution to $0.1 \mathrm{wt}$ $\%$ favored the formation of MMs over the formation of $\mathrm{H}$ terminated polymer. Changing the equivalents of $\mathrm{Cu}(\mathrm{II})$, ligand, or reducing agent did not lead to significant changes in the outcome of the reaction, nor did further dilution until 0.02 wt \%. Thus, a formation of roughly $80 \%$ MM species (consisting both of $\mathrm{MM}^{\mathrm{X}}$ and $\mathrm{MM}^{\mathrm{H}}$ ) appears to be the maximum of what can be reached with respect to the synthetic goal of the experiments. It can hence be concluded that the AGET activation of ATRP-made polyacrylate is indeed capable to produce macromonomers with reduced polydispersity, but only in small amounts per batch and lower functional fidelity of end groups compared to the conventional method, even though $80 \%$ appears to be acceptable. For future studies such product is still an important material. In many previous studies on 

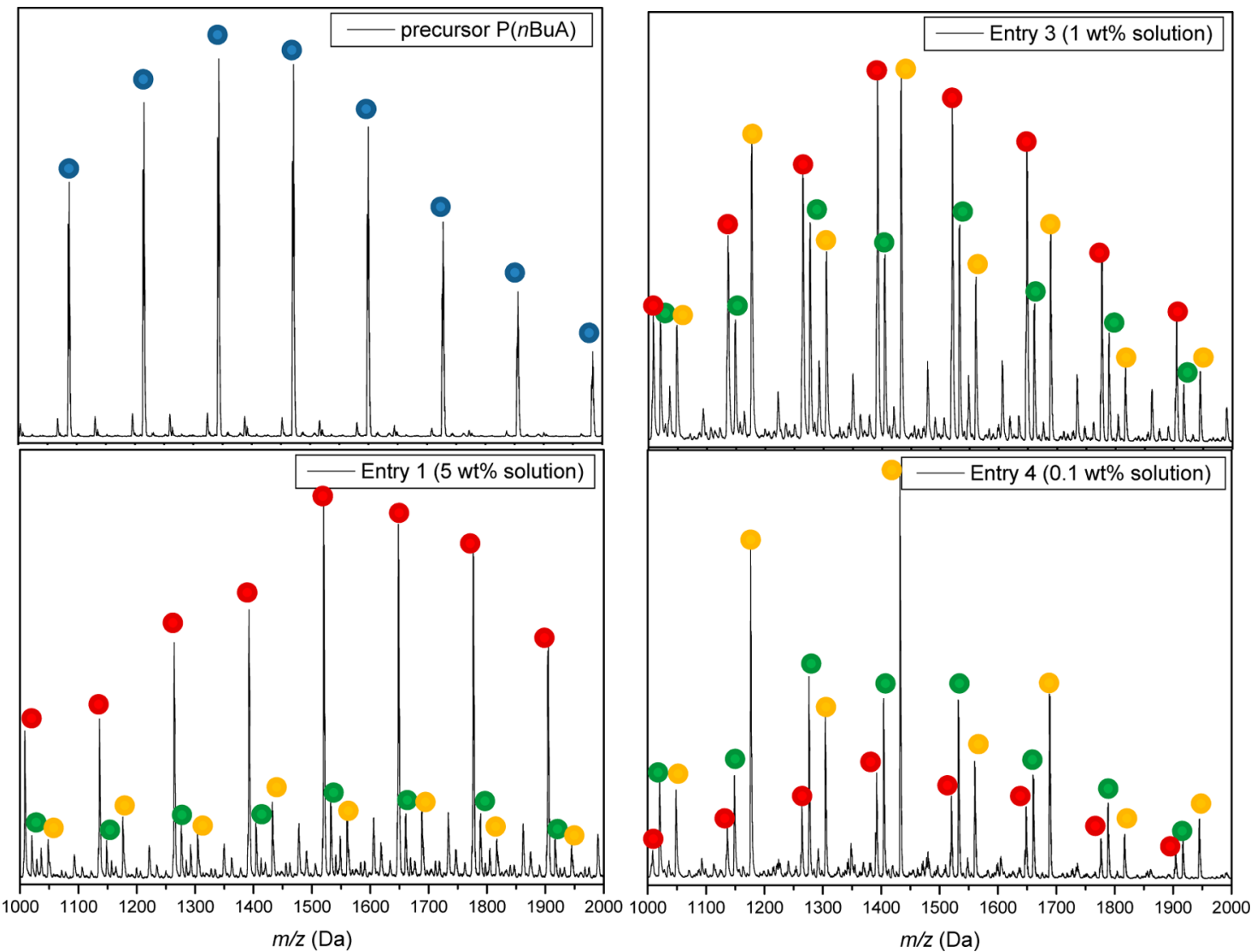

Figure 3. ESI-MS spectra of precursor $\mathrm{P}(n \mathrm{BuA})$ and of macromonomer mixtures synthesized in different dilutions at $140{ }^{\circ} \mathrm{C}$ via $\mathrm{AGET}$ activation.

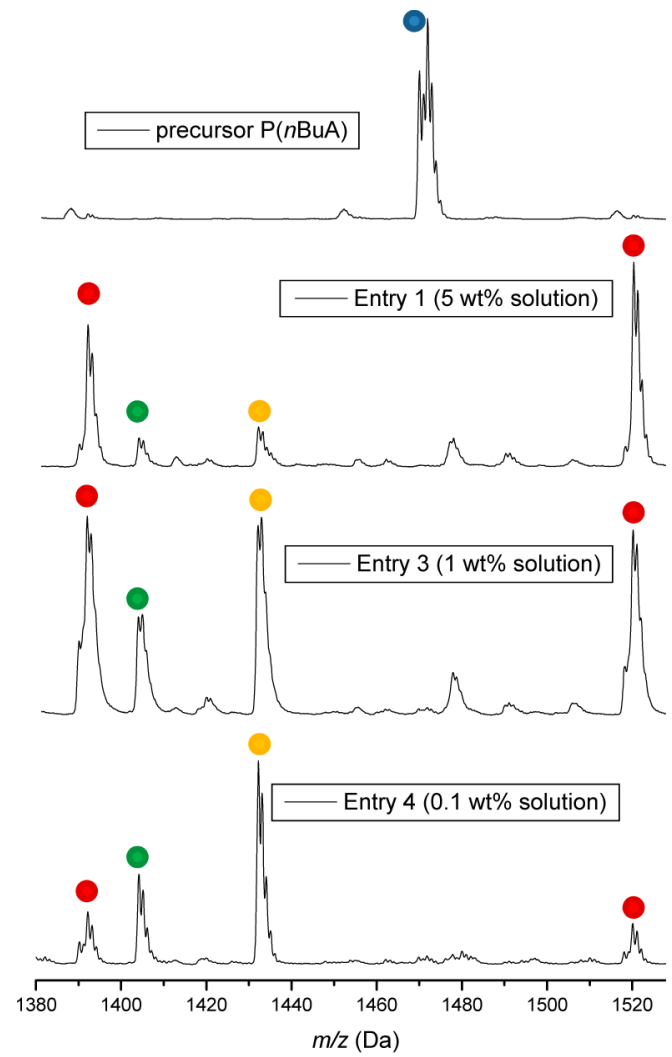

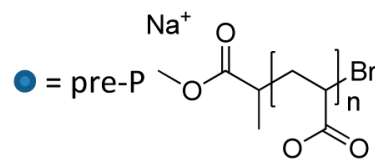<smiles>C=C(CC(C)CC(C)(C)C(=O)OCCCC)C(=O)OCCCC</smiles><smiles>COC(=O)C(C)(C)CC(C)C(=O)O</smiles>

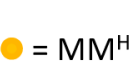<smiles>C=C(CC(C)C(=O)OCCCC)C(=O)OCCCC</smiles>

Figure 4. Left: ESI-MS spectra of single monomer repeating units in the distributions depicted in Figure 3. Right: structures of species observed in ESI-MS spectra of precursor $\mathrm{P}(n \mathrm{BuA})$ and of macromonomer mixtures synthesized in different dilutions at $140{ }^{\circ} \mathrm{C}$ via AGET activation. 
Table 2. Table of Masses for Products Identified in the Mass Spectra

\begin{tabular}{lccc}
\multicolumn{1}{c}{ species } & $m / z_{\text {theo }}(\mathrm{Da})$ & $m / z_{\text {exp }}(\mathrm{Da})$ & $\Delta m / z(\mathrm{Da})$ \\
precursor $\mathrm{P}(n \mathrm{BuA})$ & 1471.79 & 1471.58 & 0.21 \\
$\mathrm{H}$-transfer polymer & 1391.88 & 1392.08 & 0.20 \\
$\mathrm{MM}^{\mathrm{X}}$ & 1403.88 & 1404.17 & 0.29 \\
$\mathrm{MM}^{\mathrm{H}}$ & 1431.90 & 1432.25 & 0.35 \\
\hline
\end{tabular}

acrylate MMs the polydispersity was a limiting factor in understanding the exact mechanism of MM reactions, ${ }^{31,38,39}$ which can now be overcome, even if the synthetic effort is somewhat higher.

The results obtained by mass spectrometry contain, however, much more detailed information other than the change in transfer to MM product ratio. A remarkable observation from all ESI-MS spectra is that some $\mathrm{MM}^{\mathrm{H}}$ peaks have much higher intensity then others. Apparently, $\mathrm{MM}^{\mathrm{H}} \mathrm{s}$ with an uneven number of monomer repeating units are formed to a greater extent than $\mathrm{MM}^{\mathrm{H}} \mathrm{s}$ with an even number of monomer units. No such change can be seen for $\mathrm{MM}^{\mathrm{X}}$. This observation points to the fact that besides the random chain transfer and 6membered ring backbiting/ $\beta$-scission, an additional size specific mechanism for $\mathrm{MM}^{\mathrm{H}}$ formation must be taking place, one that favors generation of chains of distinct chain lengths. Since the precursor material is randomly distributed, no random reaction can create such a specific pattern. The only reaction known to proceed always over two monomer units specifically is classical backbiting reaction. If only occurring once, still no selective distribution would be generated, but if migration along the polymer backbone of the MCR via 6-membered ring backbiting steps is assumed, then the selectiveness can be explained for $\mathrm{MM}^{\mathrm{H}}$ (when the MCR migrates, only the proton-terminated side from where the MCR is traveling has a favored length) and concomitantly why $\mathrm{MM}^{\mathrm{X}}$ exhibits normally distributed patterns. The postulated mechanism is depicted in Scheme 2. At first, a MCR is formed via backbiting via a six-membered ring transition structure. Second, the polymer chain can reorient itself in such a way that the secondary radical could undergo a second six-membered ring backbiting step, thereby shifting the MCR two monomer units further along the backbone. As a result of this process, $\beta$-scission on this variety of MCRs will lead to an accumulation of $\mathrm{MM}^{\mathrm{H}} \mathrm{s}$ with an uneven number of monomer repeating units, exactly as observed in the ESI-MS spectra.

The effect of the size-selective $\mathrm{MM}^{\mathrm{H}}$ production becomes more evident with decreasing polymer concentration. This can easily be explained by the fact that lifetimes of the MCR increase with increasing dilutions. Thus, more time for a travel of the MCR is given, which also well explains why progressively smaller molecular weights are observed with dilution of the polymer. For the most intense peaks observed in ESI-MS (corresponding to $\mathrm{MM}^{\mathrm{H}}$ species with 11 or 13 monomer units), 5 or 6 consecutive migration steps must have occurred prior to the final $\beta$-scission reaction. MCR migration has several consequences. Not only a size selection is induced, also the distribution of MCRs over the whole chain becomes a function of the average MCR lifetime. In the above experiments one can see that still a large proportion of chains is generated via random transfer as seen by the $\mathrm{MM}^{\mathrm{H}}$ chains with even number of chain segments.

\section{CONCLUSIONS}

In this study, we aimed at making uniform, low-polydispersity MMs via reactivating ATRP $\mathrm{P}(n \mathrm{BuA})$ precursors, using AGET conditions at temperatures of $140{ }^{\circ} \mathrm{C}$. At these high temperatures, the generated $\mathrm{P}(n \mathrm{BuA})$ macroradicals undergo chain transfer into MCRs, followed by $\beta$-scission reactions, forming unsaturated macromonomers. Thorough characterization of the formed products via NMR, SEC, and ESI-MS revealed some intriguing observations. First of all, besides successful MM formation, also $\mathrm{H}$-transfer reactions take place, which can only be reduced to satisfactory levels when diluting the reaction mixtures to $0.1 \mathrm{wt} \%$. Second, clear shifts of SEC chromatograms toward lower molar masses reveals that under these reaction conditions MMs are not only formed through simple backbiting $/ \beta$-scission via six-membered ring transition structures, but that random transfer (and MCR migration) play also a considerable role. This is also supported by the fact that two types of $\mathrm{MM}$ structures $\left(\mathrm{MM}^{\mathrm{H}}\right.$ and $\left.\mathrm{MM}^{\mathrm{X}}\right)$ are found in the product pattern recorded by ESI-MS, instead of only $\mathrm{MM}^{\mathrm{X}}$, which would be the case if random chain transfer was negligible. Finally, a size selective reaction pathway was observed, favoring the generation of $\mathrm{MM}^{\mathrm{H}} \mathrm{s}$ with an uneven number of monomer repeating units. To this end, a MCR migration process was formulated, whereby MCRs can travel along the polymer backbone. Such reaction had been proposed before based on ESR studies ${ }^{40,41}$ but was in here for the first time directly experimentally observed using soft ionization mass spectrometry. All results in the present study point to the conclusion that backbiting via six-membered ring structures is indeed the most important process in acrylate transfer to polymer reactions but that its consequences must be reconsidered in future studies. Also, semiquantitative data for the random transfer are given, demonstrating that its influence-as was already indicated in many recent simulation studies from our and other laboratories-should not be underestimated. Regarding intermolecular transfer also interesting data have been gathered, but certainly more in-depth studies will be required to extract kinetic rate coefficients, which will be subject of future studies.

\section{AUTHOR INFORMATION}

\section{Corresponding Author}

*E-mail thomas.junkers@uhasselt.be; Tel +32(11)268318; Fax +32(11)268399.

\section{Notes}

The authors declare no competing financial interest.

\section{ACKNOWLEDGMENTS}

The authors are grateful for award of the Odysseus project "Precise Polymer Design for the Development of New Materials" by the Fund for Scientific Research-Flanders (FWO).

\section{REFERENCES}

(1) Chiefari, J.; Chong, Y. K.; Ercole, F.; Krstina, J.; Jeffery, J.; Le, T. P. T.; Mayadunne, R. T. A.; Meijs, G. F.; Moad, C. L.; Moad, G.; Rizzardo, E.; Thang, S. H. Macromolecules 1998, 31, 5559-5562.

(2) Moad, G.; Barner-Kowollik, C. The Mechanism and Kinetics of the RAFT Process. In Handbook of RAFT Polymerization; BarnerKowollik, C., Ed.; Wiley-VCH: Weinheim, 2008.

(3) Matyjaszewski, K.; Xia, J. Chem. Rev. 2001, 101, 2921-2990.

(4) Hawker, C. J.; Bosman, A. W.; Harth, E. Chem. Rev. 2001, 301, $3661-3688$. 
(5) Debuigne, A.; Hurtgen, M.; Detrembleur, C.; Jérôme, C.; BarnerKowollik, C.; Junkers, T. Prog. Polym. Sci. 2012, 37, 1004-1030.

(6) Kolb, H. C.; Finn, M. G.; Sharpless, K. B. Angew. Chem., Int. Ed. 2001, 40, 2004-2021.

(7) Binder, W. H.; Sachsenhofer, R. Macromol. Rapid Commun. 2008, 29, 952-981.

(8) Evans, R. A. Aust. J. Chem. 2007, 60, 384-395.

(9) Barner-Kowollik, C.; Inglis, A. J. Macromol. Chem. Phys. 2009, 201, 987-992.

(10) Zorn, A.-M.; Malkoch, M.; Carlmark, A.; Barner-Kowollik, C. Polym. Chem. 2011, 2, 1163-1173.

(11) Hadjichristidis, N.; Pitsikalis, M.; Iatrou, H.; Pispas, S. Macromol. Rapid Commun. 2003, 24, 979-1013.

(12) Schön, F.; Hartenstein, M.; Müller, A. H. E. Macromolecules 2001, 34, 5394-5397.

(13) Topham, P. D.; Sandon, N.; Read, E. S.; Madsen, J.; Ryan, A. J.; Armes, S. P. Macromolecules 2008, 41, 9542-9547.

(14) Yamada, B.; Zetterlund, P. B.; Sato, E. Prog. Polym. Sci. 2006, 31, 835-877.

(15) Chiefari, J.; Jeffery, J.; Mayadunne, R. T. A.; Moad, G.; Rizzardo, E.; Thang, S. H. Controlled/Living Radical Polymerization: Progress in ATRP, NMP and RAFT; ACS Symposium Series 768; Matyjaszewski, K., Ed.; American Chemical Society: Washington, DC, 2000; Chapter 21, pp 297-312.

(16) Li, D.; Grady, M. C.; Hutchinson, R. A. Ind. Eng. Chem. Res. 2005, 44, 2506-2517.

(17) Quan, C. L.; Soroush, M.; Grady, M. C.; Hansen, J. E.; Simonsick, W. J. Macromolecules 2005, 38, 7619-7628.

(18) Grady, M. C.; Simonsick, W. J.; Hutchinson, R. A. Macromol. Symp. 2002, 182, 149-168.

(19) Chiefari, J.; Jeffery, J.; Mayadunne, R. T. A.; Moad, G.; Rizzardo, E.; Thang, S. H. Macromolecules 1999, 32, 7700-7702.

(20) Chiefari, J.; Moad, G.; Rizzardo, E.; Gridnev, A. A. US 98/ 47927, 1998.

(21) Junkers, T.; Barner-Kowollik, C. J. Polym. Sci., Part A: Polym. Chem. 2008, 46, 7585-7605.

(22) Willemse, R. X. E.; van Herk, A. M.; Panchenko, E.; Junkers, T.; Buback, M. Macromolecules 2005, 38, 5098-5103.

(23) Nikitin, A. N.; Hutchinson, R. A.; Buback, M.; Hesse, P. Macromolecules 2007, 40, 8631-8641.

(24) Junkers, T.; Bennet, F.; Koo, S. P. S.; Barner-Kowollik, C. J. Polym. Sci., Part A: Polym. Chem. 2008, 46, 3433-3437.

(25) Barner-Kowollik, C.; Davis, T. P.; Stenzel, M. H. Polymer 2004, 45, 7791-7805.

(26) Koo, S. P. S.; Junkers, T.; Barner-Kowollik, C. Macromolecules 2009, 42, 62-69.

(27) Junkers, T.; Koo, S. P. S.; Davis, T. P.; Stenzel, M. H.; BarnerKowollik, C. Macromolecules 2007, 40, 8906-8912.

(28) Junkers, T.; Barner-Kowollik, C. Macromol. Theory Simul. 2009, $18,421-433$.

(29) Barner-Kowollik, C.; Junkers, T. J. Polym. Sci., Polym. Chem. 2011, 49, 1293-1297.

(30) Zorn, A.-M.; Junkers, T.; Barner-Kowollik, C. Macromol. Rapid Commun. 2009, 30, 2028-2035.

(31) Zorn, A.-M.; Junkers, T.; Barner-Kowollik, C. Macromolecules 2011, 44, 6691-6700.

(32) Zorn, A. M.; Barner-Kowollik, C. J. Polym. Sci., Part A: Polym. Chem. 2012, 50, 2366-2377.

(33) Jakubowski, W.; Matyjaszewski, K. Macromolecules 2005, 38, $4139-4116$

(34) Min, K.; Jakubowski, W.; Matyjaszewski, K. Macromol. Rapid Commun. 2006, 27, 594-598.

(35) Debuigne, A.; Hurtgen, M.; Detrembleur, C.; Jérôme, C.; Barner-Kowollik, C.; Junkers, T. Prog. Polym. Sci. 2012, 37, 10041030.

(36) Xia, J.; Gaynor, S. G.; Matyjaszewski, K. Macromolecules 1998, 31, 5958-5959.

(37) Dossi, M.; Storti, G.; Moscatelli, D. Macromol. Symp. 2010, 289, 119-123.
(38) Koo, S. P. S.; Stamenović, M. M.; Prasath, R. A.; Inglis, A. J.; Du Prez, F. E.; Barner-Kowollik, C.; Van Camp, W.; Junkers, T. J. Polym. Sci., Polym. Chem. 2010, 48, 1699-1713.

(39) Barth, J.; Buback, M.; Barner-Kowollik, C.; Junkers, T.; Russell, G. T. J. Polym. Sci., Polym. Chem. 2012, DOI: 10.1002/pola.26295.

(40) Kajiwara, A. Macromol. Symp. 2007, 248, 50-59.

(41) Kajiwara, A. Controlled/Living Radical Polymerization: Progress in ATRP; ACS Symposium Series 1023; Matyjaszewski, K., Ed.; American Chemical Society: Washington, DC, 2009; Chapter 4, pp $49-59$. 